\title{
Exploring how innovation strategies at time of crisis influence performance: a cluster analysis perspective
}

\author{
Marcel Ausloos ${ }^{\mathrm{a}, \mathrm{b}}$, Francesca Bartolaccic ${ }^{\mathrm{c}}$, Nicola G. Castellano ${ }^{\mathrm{d}}$, Roy Cerqueti ${ }^{\mathrm{e}}$

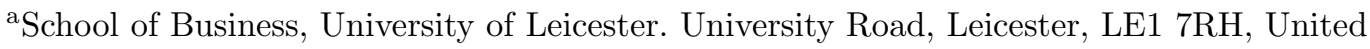 \\ Kingdom. Email: ma683@le.ac.uk \\ ${ }^{\mathrm{b}}$ GRAPES. rue de la Belle Jardiniere, 483/0021, B-4031, Liege Angleur, Belgium, Euroland. \\ Email: marcel.ausloos@ulg.ac.be \\ ${ }^{c}$ Department of Economics and Law, University of Macerata. Via Crescimbeni, 20, I-62100 \\ Macerata, Italy. Email: framcesca.bartolacci@unimc.it \\ ${ }^{\mathrm{d}}$ Department of Economics and Law, University of Macerata. Via Crescimbeni, 20, I-62100, \\ Macerata, Italy. Email: nicola.castellano@unimc.it \\ eDepartment of Economics and Law, University of Macerata. Via Crescimbeni, 20, I-62100 \\ Macerata, Italy. Email: roy.cerqueti@unimc.it
}

\author{
ARTICLE HISTORY \\ Compiled May 29, 2017
}

\begin{abstract}
This paper analyzes the connection between innovation activities of companies implemented before crisis - and their performance - measured at time of crisis. The companies listed in the STAR Market Segment of the Italian Stock Exchange are analyzed. Innovation is measured through the level of investments in total tangible and intangible fixed assets in 2006-2007, while performance is captured through growth - expressed by variations of sales, total assets and employees - profitability - through ROI or ROS - and productivity - through asset turnover or sales per employee in the period 2008-2010. The variables of interest are analyzed and compared through statistical techniques and by adopting cluster analysis. In particular, a Voronoi tessellation is also implemented in a varying centroids framework. In accord with a large part of the literature, we find that the behavior of the performance of the companies is not univocal when they innovate.
\end{abstract}

\section{KEYWORDS}

Innovation, business performance, financial statements, STAR Market, cluster analysis, Voronoi tessellation.

\section{Introduction}

The efforts spent by the entrepreneurs in innovation initiatives have the specific target of contributing to enhance companies' performances. However, the real effect of innovation on performance is still at the center of the academic debate, also for the practical implications of this theme. Furthermore, the influence of the status of the economic environment is also of paramount relevance for the complete understanding

Corresponding author: Roy Cerqueti - Department of Economics and Law, University of Macerata. Via Crescimbeni, 20, I-62100 Macerata, Italy. Email: roy.cerqueti@unimc.it. Tel.: +39 0733 2583246; Fax: +39 07332583205 . 
of such a relationship.

The present research aims at exploring the connection between innovation strategy and performance of a company at time of a global economic crisis. In our specific context, innovation is derived from empirical data and is captured by the level of investments in innovation activities. Thus, we will split such a conceptualization into tangible and intangible assets, as we will see below. In our study, the relationship between various innovation initiatives and performance measures of Italian companies is investigated from quantitative information available in their publicized consolidated financial statements. Specifically, we deal with the whole set of companies listed in the STAR market segment of Italian Stock Exchange.

Such a market includes only "mid-sized companies" in terms of capitalization. Hence, the investigated sample is coherent with a common sense aim that the impacts produced by innovation on performance should be more evident in companies focusing on a unique or on rather limited fields of operating activity. Moreover, the sample of such listed companies allows an exhaustive availability of financial statements information, preventing any bias due to companies selection.

We have assumed that the generation of innovation requires significant investment of resources ( Heirman and Clarysse, 2007; Renzi and Simone, 2011; Montresor and Vezzani, 2016) and have detected in 2006-2007 the presence of innovation initiatives represented by investment level on intangible and tangible fixed assets (OECD 2005, p. 35 ). Indeed, even if these measures do not cover all aspects of innovation, they surely represent a significant part of it (see OECD 2005, p. 40). Furthermore the employment of financial measures to quantify innovation is widely accepted (see e.g. Chun et al. 2015; Gocer et al. 2016; Baum et al., 2017; Ceptureanu et al., 2017). We follow such a line of thought. In the 2008-2010 post-crisis time interval, the performance outcomes are measured through (i) growth (or decay) variations: those of sales, total assets and number of employees; (ii) profitability: return on investment (ROI) and return on sales (ROS); (iii) efficiency: assets turnover and sales per employee. The time-horizon is consistent with the good practice of productivity in analyzing the effects of innovation on performance, as clearly declared by OECD 2005. Specifically, we take into account aggregated indicators for growth, profitability and productivity.

Bartolacci et al. (2015) employ the same sample analyzed here and discuss the effects of innovation on performance through a new class of entropy measures. In particular, the quoted paper seeks the similarities between companies in terms of the disorder generated by their classifications.

Also the present study is based on a cluster analysis of firm-level data - the STAR market companies are not homogenous neither in terms of industry nor for the propensity to innovate. Nevertheless, the heterogeneity can be viewed as a bonus allowing for a credible focus due to some independence of market constraints specific to a industry segment.

However, we differ from Bartolacci et al. (2015) since we propose a formal and rather original method, based on Voronoi tessellation (Voronoi, 1908). Such a statistical tool consists of the a-priori definition of some reference points - namely, centroids - and of a distance measure, and each centroid identifies a cluster whose elements have distance smaller to it than to the other centroids.

We depart from the original formulation of Voronoi by introducing a concept of weighted Euclidean distance, hence leading to asymmetry (see formulas (2) and (3)). In so doing, we specify different relative relevance to the variables, hence gaining insights from the analysis.

Within the clusters, one could compare the characteristics and performance of com- 
panies holding the same innovation level, whereas between the clusters heterogeneity means that different innovation levels might be suitable for obtaining different levels of performance. In this respect, cluster analysis seems to be particularly effective in providing a global analysis of the relationship between innovation and performance but also a disaggregated discussion of the single units and of the clusters.

Due to its versatility, the proposed methodology has been applied in several scientific fields, like neuroscience (see e.g. Duyckaerts and Godefroy, 2000), astrophysics (see e.g. Ramella et al., 2001) and material science (see e.g. Gadomski and Kruszewska, 2012).

However, the use of Voronoi tessellation is quite neglected in the management literature. Applications of this technique to economic themes can be found in Liu et al. (2009), Yushimito et al. (2012) and Vaz et al. (2014). Hence, this paper contributes to fill the gap between complex science and management.

More generally, the paper is in line with a large strand of economic literature. Indeed, clustering techniques are largely employed to analyse the performance at country, industrial district or firm level (see e.g. Zahra and Covin, 1994; Gligor and Ausloos, 2007, 2008a, 2008b). Furthermore, in some cases the cluster analysis is employed to investigate the determinants of innovation and innovation-performance focused on a single industry (Tseng et al., 2008), a single country (Dwyer and Mellor, 1993; Vaz et al., 2014; Agostini et al., 2015), or different industries and/or countries (Pavitt, 1984; Cesaratto and Mangano, 1993; Leiponen and Drejer, 2007).

The paper is structured as follows: Section 2 contains a summary of extant literature about innovation and performance and the research questions developed accordingly; Section 3 describes the dataset and the explanatory variables; Section 4 outlines the employed methodology; Section 5 states and discusses the main results. Last section concludes.

\section{Innovation and performance: literature review and research question}

Scholars generally investigate the characteristics associated to innovative companies, or the relationships expected between innovation and performance. In several cases the analyses are combined. Such studies are of classificatory and predictive kind.

In the first stream of research Khan and Manopichetwattana (1989) investigate innovativeness in small and medium companies, in association to a set of characteristics (environmental, organizational, entrepreneurial, etc.). They find that the inclination to collect information about the external environment is positively associated with innovation. Similarly, positive impacts on innovation are produced by environmental dynamism or heterogeneity.

The pioneering paper of Pavitt (1984) classifies companies according to their innovative activities by using an inductive methodological approach (Archibugi, 2001). Pavitt's taxonomy, over time, inspired numerous scholars applying cluster analysis with the aim to classify firms according to how intensively they innovate in order to investigate the effects on performance (Cesaratto and Mangano, 1993; Dwyer and Mellor, 1993; Hollenstein, 2003; De Jong and Marsili, 2006; Leiponen and Drejer, 2007; Jensen et al., 2007) In many cases, these works are based on innovation and performance firms data and they consistently show a heterogeneous behaviour among companies.

Cooper (1984) adopts a cluster analysis to measure the performance achieved by product innovation and identify the strategies leading to different types of performance. Obtained results show that new product performance is largely decided by the policy 
that top management elects in a specific context.

Hollenstein (2003), studying innovation modes in the Swiss service sector, finds an unclear association between innovation intensity and performance, probably due to the impact produced by other significant determinants of performance. Dwyer and Mellor (1993) come to similar results after studying five alternative strategic approaches to product innovation which produce a similar rate of success and profitability. Leiponen and Drejer (2007) highlight how different industries behave in terms of company innovation; this suggests that the characterizing features of the firms, like strategic behaviors or local search activities, are associated to a technological framework leading to short term performance inhomogeneity. In this respect, Srholec and Verspagen (2012) show that heterogeneity of firms at a sectoral and country level is the key to understand why companies behave differently when they innovate. Shin et al (2017) in their recent study find that the effect produced by innovation, measured in terms of $R \& D$ intensity, on performance is influenced by the level of vertical integration: in particular, less integrated companies may focus on a limited part of the innovation process thereby increasing their profitability compared to more integrated companies of the same industry.

Performance heterogeneity may be related to technological innovation, as shown by several works in reference to many industrialized countries and industries (Brusoni et al., 2006; Lawless and Anderson, 1996; Kirner et al., 2009). Park et al. (2012) introduce a strategic dimension in order to explain heterogeneous performance in innovative companies, and they find that technology-oriented companies - compared to market oriented ones - are more likely to achieve instant performances since, their strategic focus on the products and services requested by customers allows managers to strengthen the customer loyalty.

At country level, Sterlacchini and Venturini (2014) compare Italian and Spanish companies over a long time period (1980-2006) and find that $R \& D$ is a crucial driver of manufacturing productivity, and this is also supported in countries generally classified as technology followers.

Cesaratto and Mangano (1993) highlight the variety of behaviours among and within sectors, and so the absence of a balance between the resources invested in innovation, quantity and quality of innovative output and economic financial performance.

Among the variables affecting the relation between innovation and performance, the presence of distress of the economic environment may play a significant role (Ranga and Etzkowitz, 2012; Nunes and Lopes, 2015). Due to the recent European crisis numerous companies face stronger difficulties into achieving good financial performance and in investing resources to promote innovation (Filippetti and Archibugi, 2011; Filippetti et al., 2013). Crises acts as a disruptor of economic activities, and innovation may be considered both as a privileged dimension of the policy response to them (OECD, 2009) and also one of the most significant drivers of competitiveness. For that reason an analysis of the impact produced by innovation in time of crisis may provide interesting additional insight to literature. Accordingly, we formulate the following research question:

RQ. Do innovation initiatives, even promoted in time of crisis, produce heterogeneous financial performance? 


\section{Data}

The analysis is performed over the companies listed in the STAR Market which included, as of 31 December, 2010, 71 companies of mid-size in terms of capitalization value (between 40 million and 1 billion euros). However, to be consistent, banks and insurance institutes have been removed from the collected sample, hence leading to 62 companies. Data have been manually collected from the consolidated section of the annual reports of the companies, and taken from the companies' websites. The spanned period is 2006-2010.

Biennium 2006-2007 is the reference pre-crisis period for assessing the level of innovation of the companies. Innovation is measured by using two types of indicators, i.e.: the level of tangible and intangible fixed assets. As discussed in the introduction, these indicators do not strictly limit "innovation" to "new technology implementation" (like through buying patents). We consider "innovation" in a more general sense. Specifically, tangible assets are intended as the aggregation of the balance sheet items: plants, machineries and equipments, while we have excluded properties, whose variations are not necessarily associated to innovation; intangible assets are obtained by summing items like development costs, patents, trademarks, licences and concessions, while goodwill is not taken into account: it can be driven by mergers or acquisition of new companies.

The triennium 2008-2010 is the time-span - at time of crisis - related to the performance. Such performances are measured through three growth (or decay) variations, i.e. sales variations, total assets variations, and number of employees variations; two profitability indicators, i.e. Return on investment (ROI) and Return on sales (ROS); two efficiency indicators, i.e. assets turnover and sales per employee.

Without loosing too much information and to gain empirical tractability of the problem, data have been properly treated. Specifically, in a first study, innovation and performance variables have been averaged over the reference period.

\subsection{Notations}

The following notations have been adopted.

- TIAXyy represents the level of total intangible assets (excluding goodwill) in year 20yy;

- TTAyy is the level of total tangible assets (excluding properties) in year 20yy;

- DSalyy stands for sales variations in year 20yy

- DAssyy is total assets variations, in year 20yy

- DLabyy means employees variations, in year 20yy

- ROIyy is the ROI in year 20yy

- ROSyy is the ROS in year $20 y y$

- ATOyy represents asset turnover, in year 20yy

- S/Eyy stands for sales per employee, in year 20yy

The first two items are those related to innovation, while the remaining seven ones rely on performance.

Innovation terms are averaged over the period 2006-2007, while the others in the triennium 2008-2010.

The adopted notations are:

- $<$ TIAX $>_{2}$ is the average total intangible asset (excluding goodwill) over 2 years: 
[2006-2007];

- $<\mathrm{TTA}\rangle_{2}$ represents the average of the total tangible assets (excluding properties) over 2 years: [2006-2007];

- $<$ DSal $>_{3}$ is the average of the sales variations over 3 years: [2008-2010];

- $<$ DAss $>_{3}$ is the average of the total assets variations over 3 years: [2008-2010];

- $<$ DLab $\rangle_{3} 0$ represents the average of the number of employees variations over 3 years: [2008-2010];

- $<$ ROI $>_{3}$ is the averaged ROI over 3 years: [2008-2010];

- $<$ ROS $>_{3}$ represents the averaged ROS over 3 years: [2008-2010];

- $<\mathrm{ATO}>_{3}$ is the average of the asset turnovers over 3 years: [2008-2010];

- $<\mathrm{S} / \mathrm{E}>_{3}$ represents the averaged sales per employee over 3 years: [2008-2010].

\section{Methodology}

The clustering procedure we implement is based on the Voronoi tessellation, with an asymmetric generalization of the Euclidean distance. We adapt such methodology to our specific setting.

The final target we have is to compare the companies with respect to the clusters where they are collected. The clustering procedure is implemented twice: one for the innovation variables, averaged over the biennium [2006-2007], and the other for the performance variables, averaged over the triennium [2008-2010].

In order to avoid scale effects and to be consistent, the variables of interest have been normalized in the respect of their range of variation. Formally, for each company $j=1, \ldots, 62$, we define:

$$
\bar{x}_{j}=\frac{x_{j}-m_{x}}{M_{x}-m_{x}}
$$

where $x$ is the averaged quantity of interest among the nine innovation and performance variables, the quantity $x_{j}$ represents the value of the variable $x$ for the $j$-th company and

$$
m_{x}=\min _{j=1, \ldots, 62} x_{j}, \quad M_{x}=\max _{j=1, \ldots, 62} x_{j} .
$$

The clustering procedures are then applied to the set of innovation variables $\mathcal{I}$ and to the set $\mathcal{P}$ collecting the remaining variables, which are the performance ones. All the variables are normalized, according to (1) and averaged over the reference period.

The centroids of the Voronoi tessellation are positive numbers and will be denoted as $\left\{\phi_{h}\right\}_{h=1}^{H}$ and $\left\{\psi_{k}\right\}_{k=1}^{K}$, where $H$ and $K$ are opportunely chosen integers, for the case of innovation and performance variables, respectively. The ranges of variation of the centroids depends on the selected distance measure, as we will see soon.

We now introduce the weighted Euclidean distance used for the proposed generalized Voronoi tessellation. Specifically, for the innovation variables we define:

$$
d_{\mathcal{I}}\left(j, \phi_{h}\right)=\sum_{x \in \mathcal{I}} \alpha_{x}\left(\bar{x}_{j}-\phi_{h}\right)^{2}
$$


for each centroid $\phi_{h}$ and where the $\alpha$ 's are the nonnegative weights of the norm, so that

$$
\sum_{x \in \mathcal{I}} \alpha_{x}=1
$$

Analogously, for the performance variables we define:

$$
d_{\mathcal{P}}\left(j, \psi_{k}\right)=\sum_{x \in \mathcal{P}} \beta_{x}\left(\bar{x}_{j}-\psi_{h}\right)^{2}
$$

for each centroid $\psi_{k}$ and

$$
\sum_{x \in \mathcal{P}} \beta_{x}=1
$$

By definition, we have that $0 \leq d_{\mathcal{I}}\left(j, \phi_{h}\right), d_{\mathcal{P}}\left(j, \psi_{k}\right) \leq 1$, for each company $j$ and centroid $\phi_{h}$ and $\psi_{k}$.

The generic Voronoi cell is denoted as $V_{h}^{\prime}$ and $V_{k}^{\prime \prime}$ for innovation and performance variables, respectively, where:

$$
\begin{gathered}
V_{h}^{\prime}=\left\{j=1, \ldots, 62 \mid d_{\mathcal{I}}\left(j, \phi_{h}\right)<d_{\mathcal{I}}\left(j, \phi_{\bar{h}}\right), \forall \bar{h} \neq h\right\} ; \\
V_{k}^{\prime \prime}=\left\{j=1, \ldots, 62 \mid d_{\mathcal{P}}\left(j, \psi_{k}\right)<d_{\mathcal{P}}\left(j, \psi_{\bar{k}}\right), \forall \bar{k} \neq k\right\} .
\end{gathered}
$$

Of course, the interiors of $V^{\prime}$ 's are disjoint sets, so as the $V^{\prime \prime}$ 's. Moreover,

$$
\bigcup_{h=1}^{H} V_{h}^{\prime}=\bigcup_{k=1}^{K} V_{k}^{\prime \prime}=\{1, \ldots, 62\} .
$$

\subsection{Specifications of the cluster analysis}

As a premise, it is important to point out that the cardinality of the Voronoi regions might change as the centroids do. Furthermore, the belonging of the $j$-th company to specific regions provides information on the level of innovation and on the performance of $j$.

We have implemented the Voronoi cluster analysis under different scenarios. For comparison purposes, we have always set $H=K$. The analyzed cases are now listed:

$I H=K=4,\left\{\phi_{h}\right\}_{h=1}^{H}=\left\{\psi_{k}\right\}_{k=1}^{K}=\{1 / 5,2 / 5,3 / 5,4 / 5\}$. Only one of the $\alpha$ 's and $\beta$ 's is one, while the values of the others terms are null. In this case, we explore the clustering of the companies on the basis of all the individual variables.

II $H=K=4,\left\{\phi_{h}\right\}_{h=1}^{H}=\left\{\psi_{k}\right\}_{k=1}^{K}=\{1 / 5,2 / 5,3 / 5,4 / 5\}, \alpha_{x}=1 / 2$ for each $x \in \mathcal{I}$ and $\beta_{x}=1 / 7$ for each $x \in \mathcal{P}$. This is a uniform in value case, where the definition of the centroids is made by considering a uniform decomposition of the interval $[0,1]$ and all the variables are assumed to equally concur in the Voronoi distance.

III $H=K=4,\left\{\phi_{h}\right\}_{h=1}^{H}=\left\{\psi_{k}\right\}_{k=1}^{K}=\{1 / 5,2 / 5,3 / 5,4 / 5\}, \alpha_{x}=1 / 2$ for each $x \in \mathcal{I}$ and the same weight for the macro-variables of the performance (i.e.: 
$1 / 3$ for growth, profitability and productivity) with a uniform distribution of the weights among the variables identifying each macro-variable. Hence, since growth has three variables of interest, we assign the same value of the $\beta$ 's (i.e.: $1 / 3 \times 1 / 3$ ), while the $\beta$ 's for the variables in profitability and productivity share the same value of $1 / 3 \times 1 / 2$. This is a uniform in role case, where the definition of the centroids is made by considering a uniform decomposition of the interval $[0,1]$ and all the macro-variables for performance are assumed to equally concur in the Voronoi distance, with also equal weight for the variables identifying the three macro-variables for performance.

Scenario $I$ has led to the identification of some outliers, whose effect is to collapse the majority of the companies in the first cluster. To remove this inconsistency, 9 companies have been removed from the sample and the cluster analysis have been applied to the remaining 53 companies, with data normalized according to (1).

\section{Results and discussion}

As we will see below, our analysis leads to a positive answer to research question RQ. In fact, the overlapping of the clusters provided through the three clustering methods suggests the presence of a non straightforward relation between innovation and performance, even when innovation is performed in a period of economic crisis. Table 1 illustrates the main statistical indicators of the considered variables.

\section{INSERT TABLE 1 ABOUT HERE}

The distributions of tangible and intangible assets show similar characteristics: the standard deviation is remarkably higher than the mean, and skewness and kurtosis show that data are not normally distributed (with positive skewness and kurtosis). This shows that the analyzed companies may have chosen to adopt different innovative strategies, even if they belong to the same market segment. The same characteristics also relate to all the growth indicators, whereas profitability measures tend to a normal distribution since the median and the mean are substantially similar and skewness and kurtosis tend to zero. Within the efficiency measures, the asset turnover and sales per employee are differently distributed: the former is roughly normally distributed, while the latter shows a positive skewness and a significant peak.

In Table 2 the distribution of companies among the clusters is shown either for clustering $I I$ and for clustering $I I I$. To provide comments on the results, we denote by first cluster the one associated to the smaller centroid and, in an increasing way, the second and the third cluster, so that the fourth cluster is the one associated to the higher value of centroid.

\section{INSERT TABLE 2 ABOUT HERE}

In clustering $I I$ the same weight is assigned to all the innovation and performance indicators, whereas in the clustering $I I I$ the same weight is assigned to the perspectives employed for innovation and performance (i.e. growth, profitability and efficiency). For what concern innovation, clusterings $I I$ and $I I I$ do not produce any difference, since in both cases the same weight is assigned to innovation measures. The greatest number of companies are located in the first cluster - i.e., we recall it, the one associated to the centroid with the lower value - and a limited number of companies lie in the second and third clusters. Comparing clusterings $I I$ and $I I I$, the only difference 
is that two companies are reallocated from the first to the third cluster, meaning that the different weights assigned to growth, profitability and efficiency, as measures of performance, slightly emphasize variability. It's worth noting that no companies are located in the fourth cluster neither for innovation or performance.

In Table 3, a qualitative description of the clusters of the sample companies is provided.

\section{INSERT TABLE 3 ABOUT HERE}

The values refer to the clusterings $I I$ and $I I I$ for innovation and performance. Referring to innovation cluster, the greatest number of companies (45 out of 53) is located in the first cluster, meaning that, in relative terms, companies undertake weak innovation initiatives (at least those which produce reflections on tangible and intangible assets). Total Assets, total sales and number of employees - which are the measures largely employed in literature for company size - show that the higher the intensity of innovation, the higher the size. This is particularly true for total sales and number of employees. Also the incidence of both tangible and intangible assets (as percentage of the total assets) is increasing in the three innovation clusters, meaning that in highly innovative companies, tangible and intangible assets represent a relevant portion of the total assets disclosed. The mean/std. dev. ratio shows that the composition of the clusters is rather heterogeneous except for the 3rd innovation cluster which is composed by companies whose size is fairly concentrated around the mean. For what concern performance, the distribution of companies among the clusters is quite different from that of innovation. This provides evidence that the association between innovation and performance is not self-evident. The averages in the performance clusters also do not allow to appraise significant differences neither in terms of company size or incidence of tangible and intangible assets.

Table 4 shows the averages drivers of innovation and performance for the entire sample and referred to clustering $I I$ and $I I I$ for innovation and performance.

\section{INSERT TABLE 4 ABOUT HERE}

Looking at the innovation clustering, a comparison between the three clusters shows that, reasonably, innovation averages increase from the first to the third cluster, whereas performance averages show quite ambiguous tendencies. In the first cluster, the averages of innovation for tangible and intangible assets are below the general averages referred to the entire sample, whereas all the performance indicators are above the general averages. In the second cluster, a general under-the-general-average performance is associated to an above-the-general-average innovation. In the third cluster, the performance averages are mixed.

The mean/std. dev. ratio allows additional insights about the homogeneity within the clusters which is generally really low, meaning that as result of the clustering technique, extremely different companies lie within the same cluster both in terms of innovation and performance. The only exception is represented by asset turnover, since the std. dev. is remarkably concentrated around the average. This could be interpreted as a possible association between innovation and asset turnover, even if its direction remains unclear, since a high asset turnover is associated to a low innovation in the first cluster, whereas a low asset turnover is associated to a medium innovation in the second cluster and then again high asset turnover is associated to high innovation in the third cluster. It's worth noting that in the third cluster, companies appear rather homogeneous in terms of performance, particularly for profitability (both ROI and ROS) and efficiency (asset turnover and sales per employee). We could then ar- 
gue that, above a particular threshold of innovation intensity, the level performances seems rather homogeneous, even if it's not sure if high innovation lead to high performance. Similar considerations can be made for performance clustering. Both in the $I I$ and $I I I$ performance clustering, the performance averages gradually increase from the first to the third cluster, whereas innovation averages decrease (intangible assets) or fluctuate (tangible assets). The relation innovation-performance seems, then, quite puzzling. Even for performance clustering, heterogeneity generally occurs within the clusters except for asset turnover.

Some additional considerations may arise by considering the distances between the average values referred to the performance clusters. The indicators of growth (particularly sales variation and employee variation), show substantially an equal distance between the clusters, whereas in profitability the distance between the second and third clusters is lower than that between the second and the first ones, meaning that companies in the third cluster show performances substantially similar to companies lying in the second cluster, while an higher distance occurs for companies in the first cluster. This could probably mean that there is a low-medium innovative investment threshold that companies should overcome in order to get an increase in performance. Finally, Table 5 is created by considering the clustering method $I$, where all the innovation and performance measures are considered separately.

\section{INSERT TABLE 5 ABOUT HERE}

In order to provide a synthetic picture, data are consolidated by industry and the histograms show the distributions among the four clusters, within each industry. No substantial differences may be appraised for tangible and intangible assets, whose distributions are concentrated on the first two clusters. Differently, profitability shows high frequencies in the second and third clusters for almost all the industries. Sales per employee is the only measure of performance that shows distributions similar to those of tangible and intangible assets. This provides a slight evidence that sales per employee, among the performance indicators adopted in the study, is perhaps the most suitable measure to demonstrate the effects of innovation initiatives on performance.

\section{Conclusions}

This paper deals with the exploration of the relationship between innovation activities and firms' performance at time of crisis. The considered sample is given by the companies listed in the STAR market; the reference period is the quinquennium 2006-2010. Two innovation and seven performance variables have been manually collected from the consolidated section of the companies' annual reports.

The analysis is carried out by adopting cluster methodologies based on Voronoi tessellation. In so doing, the present paper fills an existing gap between complex science - with specific reference to cluster analysis through Voronoi diagrams - and the field of microeconomics - with peculiar attention to the relationship between innovation at time of crisis and performance. In particular, three different clustering strategies have been implemented and discussed.

Several previous contributions in this field have considered the effects of innovation strategies on performance using mainly cross-section data, often in the context of a specific sector (manufacturing or ICT, for example). The impact produced by innovation on performance in times of crisis has been rather neglected. However, our results support what literature basically asserts for non-crisis periods, i.e.: the performance 
of the companies may be sensibly heterogeneous when companies innovate.

Another important contribution of the present study is related to the employment of different performance indicators that highlight the various perspectives, not always convergent, of the business management. This allowed us to identify the sales per employee indicator as one of the most suitable measure to intercept the effects of innovation initiatives on performance, at least in our sample.

On the one hand, the motivations for such an heterogeneity remain unexplored. On the other hand, the findings suggest to continue on elaborating and arguing the relationship question by employing a Voronoi tessellation method. Of course, to sort out the various correlations, causes and effects, represents a very complex task. Working in this direction should allow better grasp on managing policies.

\section{References}

Agostini, L., Nosella, A., Soranzo, B., 2015. The impact of formal and informal appropriability regimes on SME profitability in medium high-tech industries. Technology Analysis and Strategic Management 27(4), 405-419.

Archibugi, D., 2001. Pavitt's taxonomy sixteen years on: a review article, economics of innovation and new technology, Economics of Innovation and New Technology 10(5), 415-425.

Archibugi, D., Filippetti, A., Frenz, M., 2013. Economic crisis and innovation: Is destruction prevailing over accumulation? Research Policy 42(2), 303-314.

Bartolacci, F., Castellano, N.G., Cerqueti, R., 2015. The impact of innovation on companies' performance: an entropy-based analysis of the STAR Market Segment of Italian Stock Exchange, Technology Analysis and Strategic Management 27(1), 102123.

Baum, C.F., Lööf, H., Nabavi, P., Stephan, A., 2017. A new approach to estimation of the $R \& D$-innovation-productivity relationship. Economics of Innovation and New Technology 26(1/2), 121-133.

Brusoni, S., Cefis, E., Orsenigo, L., 2006. Innovate or Die? A critical review of the literature on innovation and performance, CESPRI, Centro di Ricerca sui Processi di Innovazione e Internazionalizzazione, Universitá Commerciale Luigi Bocconi, Working Paper n. 179.

Ceptureanu, E.G., Ceptureanu, S.I., Luchian, C.E., Luchian. I., 2017. Quality Management in Project Management Consulting. A Case Study in an International Consulting Company. Amfiteatru Economic 19(44), 215-230.

Cesaratto, S., Mangano, S., 1993. Technological profiles and economic performance in the Italian manufacturing sector. Economics of Innovation and New Technology 2, 237-256.

Chun, D., Chung, Y., Bang, S., 2015. Impact of firm size and industry type on $R \& D$ efficiency throughout innovation and commercialisation stages: evidence from Korean manufacturing firms. Technology Analysis and Strategic Management 27(8), 895-909.

Cooper, R.G., 1984. The strategy-performance link in product innovation. R\& D Management 14(4), 247-259.

De Jong, J.P.J., Marsili, O., 2006. The fruit flies of innovations: A taxonomy of innovative small firms. Research Policy 35(2), 213-229.

Duyckaerts, C., Godefroy, G., 2000. Voronoi tessellation to study the numerical density and the spatial distribution of neurones. Journal of Chemical Neuroanatomy 20(1), 83-92. 
Dwyer, L., Mellor, R., 1993. Product innovation strategies and performance of australian firms. Australian Journal of Management 18(2), 159-180.

Filippetti, A., Archibugi, D., 2011. Innovation in times of crisis: National Systems of Innovation, structure, and demand. Research Policy 40(2), 179-192.

Gadomski, A. Kruszewska, N., 2012. On clean grain-boundaries involving growth of nonequilibrium crystalline-amorphous superconducting materials addressed by a phenomenological viewpoint. The European Physical Journal B 85(12), 1-8.

Gligor, M., Ausloos, M., 2007. Cluster structure of EU-15 countries derived from the correlation matrix analysis of macroeconomic index fluctuations, The European Physical Journal B 57, 139-146.

Gligor, M., Ausloos, M., 2008a. Convergence and cluster structures in EU area according to fluctuations in macroeconomic indices, Journal of Economic Integration 23, 297-330.

Gligor, M., Ausloos, M., 2008b. Clusters in weighted macroeconomic networks: the EU case. Introducing the overlapping index of GDP/capita fluctuation correlations, The European Physical Journal B 63, 533-539.

Gocer, I., Alatas, S., Peker, O., 2016. Effects of $R \& D$ and innovation on income in EU countries: new generation panel cointegration and causality analysis. Theoretical and Applied Economics 23(4), 153-164.

Heirman, A., Clarysse, B., 2007. Which tangible and intangible assets matter for innovation speed in start-ups? Journal of Product Innovation Management 24(4), 303315 .

Hitt, M.A., Hoskisson, R.E., Kim, H., 1997. International diversification: effects on innovation and firm performance in product diversified firms. Academy of Management Journal 40(4), 767-798.

Hollenstein, H., 2003. Innovation modes in the Swiss service sector: a cluster analysis based on firm-level data. Research Policy 32, 845-863.

Jensen, M.B., Johnson, B., Lorenz, E., Lundvall, B.A., 2007. Forms of knowledge and modes of innovation. Research Policy 36, 680-693.

Khan, A.M., Manopichetwattana, V., 1989. Innovative and non-innovative small firms: types and characteristics. Management Science 15(5), 597-606.

Kirner, E., Kinkel, S., Jaeger, A., 2009. Innovation paths and the innovation performance of low-technology firmsAn empirical analysis of German industry. Research Policy 38, 447-458.

Lawless, M.W., Anderson, P.C., 1996. Generational technological change: effects of innovation and local rivalry on performance. Academy of Management Journal 39(5), $1185-1217$.

Leiponen, A., Drejer, I., 2007. What exactly are technological regimes? Intraindustry heterogeneity in the organization of innovation activities. Research Policy $36,1221-1238$.

Liu, X.T., Zheng, X.Q. and Li, D.B., 2009. Voronoi Diagram-Based Research on Spatial Distribution Characteristics of Rural Settlements and Its Affecting Factors. A Case Study of Changping District, Beijing [J]. Journal of Ecology and Rural Environment 2, 007.

Montresor, S., Vezzani, A., 2016. Intangible investments and innovation propensity:

Evidence from the Innobarometer 2013. Industry and Innovation 23(4), 331-352.

Nunes, S., Lopes, R., 2015. Firm performance, innovation modes and territorial embeddedness, European Planning Studies 23(9), 1796-1826.

OECD, 2005. Annual Report, Paris: OECD Publishing.

OECD, 2009. Annual Report, Paris: OECD Publishing. 
Park, N.K., Park, U.D., Lee, J., 2012. Do the Performances of Innovative Firms Differ Depending on Market-oriented or Technology-oriented Strategies?. Industry and Innovation 19(5), 391-414.

Pavitt, K., 1984. Sectoral patterns of technical change: towards a taxonomy and a theory. Research Policy, 13, 343-373.

Ramella, M., Boschin, W., Fadda, D., Nonino, M., 2001. Finding galaxy clusters using Voronoi tessellations. Astronomy \& Astrophysics 368(3), 776-786.

Ranga, M., Etzkowitz, H., 2012. Great expectations: an innovation solution to the contemporary economic crisis. European Planning Studies 20(9), 1429-1438.

Renzi, A., Simone, C., 2011. Innovation, tangible and intangible resources: The space of slacks interaction. Strategic Change 20(1-2), 59-71.

Shin, N., Kraemer, K.L., Dedrick J., 2017. R\&D and firm performance in the semiconductor industry. Industry and Innovation 24(3), 280-297.

Srholec, M., Verspagen, B., 2012. The Voyage of the Beagle into innovation: Explorations on heterogeneity, selection, and sectors. Industrial and Corporate Change 21(5), 1221-1253.

Sterlacchini A., Venturini F., 2014. R\&D and Productivity in High-Tech Manufacturing: A Comparison between Italy and Spain. Industry and Innovation 21(5), 359-379.

Tseng, C.Y., Hui-Yueh Kuo, H-Y., Chou, S.S., 2008. Configuration of innovation and performance in the service industry: evidence from the Taiwanese hotel industry. The Service Industries Journal. 28(7), 1015-1028.

Vaz, E., de Noronha Vaz, T., Galindo, P.V., Nijkamp, P., 2014. Modelling innovation support systems for regional developmentanalysis of cluster structures in innovation in Portugal. Entrepreneurship and Regional Development 26(1-2), 23-46.

Voronoi, G.F., 1908. Nouvelles applications des paramétres continus la théorie de formes quadratiques, Journal für die reine und angewandte Mathematik 134, 198-287.

Yushimito, W.F., Jaller, M., Ukkusuri, S., 2012. A Voronoi-based heuristic algorithm for locating distribution centers in disasters. Networks and Spatial Economics 12(1), 21-39.

Zahra, S.A., Covin, J.G., 1994. Domestic and international competitive focus, technology strategy and company performance: an empirical analysis. Technology Analysis and Strategic Management 6(1), 39-54. 